\title{
Multivariate Meta-Analysis of Brain-Mass Correlations in Eutherian Mammals
}

\section{OPEN ACCESS}

Edited by:

Alberto Munoz,

Complutense University of Madrid,

Spain

Reviewed by:

Guy Elston,

Centre for Cognitive Neuroscience,

Australia

Ernestina Menasalvas,

Technical University of Madrid, Spain

*Correspondence:

Lyuba Zeh

lyuba.zehl@gmail.com

Stefan Huggenberger

st.huggenberger@uni-koeln.de

${ }^{\dagger}$ These authors have contributed equally to this work.

Received: 15 March 2016 Accepted: 13 September 2016 Published: 30 September 2016

Citation:

Steinhausen C, ZehI L, Haas-Rioth M, Morcinek K, Walkowiak W and Huggenberger S (2016) Multivariate Meta-Analysis of Brain-Mass Correlations in Eutherian Mammals.

Front. Neuroanat. 10:91. doi: 10.3389/fnana.2016.00091

\section{Charlene Steinhausen ${ }^{1,2 \dagger}$, Lyuba Zehl ${ }^{2,3 * t}$, Michaela Haas-Rioth ${ }^{4}$, Kerstin Morcinek ${ }^{1}$, Wolfgang Walkowiak ${ }^{2}$ and Stefan Huggenberger ${ }^{1,2 *}$}

${ }^{1}$ Department II of Anatomy, University of Cologne, Cologne, Germany, ${ }^{2}$ Biocenter, University of Cologne, Cologne, Germany, ${ }^{3}$ Jülich Research Centre, Institute of Neuroscience and Medicine (INM-6) and Institute for Advanced Simulation (IAS-6) and JARA BRAIN Institute I, Jülich, Germany, ${ }^{4}$ Department of Anatomy III (Dr. Senckenbergische Anatomie), Goethe University of Frankfurt am Main, Frankfurt am Main, Germany

The general assumption that brain size differences are an adequate proxy for subtler differences in brain organization turned neurobiologists toward the question why some groups of mammals such as primates, elephants, and whales have such remarkably large brains. In this meta-analysis, an extensive sample of eutherian mammals (115 species distributed in 14 orders) provided data about several different biological traits and measures of brain size such as absolute brain mass (AB), relative brain mass (RB; quotient from $A B$ and body mass), and encephalization quotient (EQ). These data were analyzed by established multivariate statistics without taking specific phylogenetic information into account. Species with high AB tend to (1) feed on protein-rich nutrition, (2) have a long lifespan, (3) delayed sexual maturity, and (4) long and rare pregnancies with small litter sizes. Animals with high RB usually have (1) a short life span, (2) reach sexual maturity early, and (3) have short and frequent gestations. Moreover, males of species with high RB also have few potential sexual partners. In contrast, animals with high EQs have (1) a high number of potential sexual partners, (2) delayed sexual maturity, and (3) rare gestations with small litter sizes. Based on these correlations, we conclude that Eutheria with either high $A B$ or high $E Q$ occupy positions at the top of the network of food chains (high trophic levels). Eutheria of low trophic levels can develop a high RB only if they have small body masses.

Keywords: eutheria, mammals, brain mass, brain size, EQ, cluster analysis, trophic level

\section{INTRODUCTION}

One of the core questions of neurobiology is how some groups of animals such as primates, elephants, and whales have evolved remarkably large brains (Haug, 1987; Marino, 1998; Roth and Dicke, 2005). Size differences of whole brains were interpreted as an adequate proxy for subtler differences in anatomy and function (Jerison, 1973; Stephan et al., 1988; van Dongen, 1998; Lefebvre et al., 2004, 2007, 2013; Marino et al., 2007). Because larger animals have larger brains (Harvey et al., 1980) but the functional or cognitive capacities of their brains are not necessarily greater, the use of absolute brain mass $(\mathrm{AB})$ to compare different species of varying body size is limited. The correlation between $\mathrm{AB}$ and body mass (BM) does not increase in a linear fashion, which means that animals of smaller sizes have a proportionally higher relative brain mass (RB) 
than larger animals (van Dongen, 1998). For these allometric reasons, the encephalization quotient (EQ), a parameter indirectly dependent on the size of a body, is an useful metric for comparing brain sizes among mammals of different size (Baron, 2007). The EQ is defined as the ratio of the actual mass of the brain to the expected brain mass given by the body mass (van Dongen, 1998).

Several comprehensive studies show that a plain correlation of brain size and its functional capacity is not valid since subtler morphological and physiological differences may explain individual adaptations of cognitive capacities (Hof et al., 2000; Manger, 2005; Roth and Dicke, 2005; Douglas and Martin, 2007; Elston, 2007; Butti et al., 2009; Shultz S. and Dunbar R. I. M., 2010; Kern et al., 2011; Dicke and Roth, 2016). Brain size may not be the main factor of functional capacities (Harrison et al., 2002; Herculano-Houzel et al., 2007; Krubitzer, 2007; Sarko et al., 2009). The increase of brain volume is usually paralleled by a structural differentiation that may result in variation in the relative size of distinctive parts of the brain (Starck, 1979; Baron et al., 1996; Voogd et al., 1998; Allman, 1999; Glickstein et al., 2007; Reep et al., 2007; Sarko et al., 2009; Shultz S. and Dunbar R. I. M., 2010). These and other authors (Elston et al., 2001; DeFelipe et al., 2002; Elston, 2002, 2007; Nedergaard et al., 2003; Sarko et al., 2009; Raghanti et al., 2015) show that the complexity and diversity of (micro-) circuits and principal neurons as well as the number of glial cells may be a main factor to influence the "computational power" of mammalian isocortices. The specification, the arrangement, and the numbers of neurons, glia cells, and neuronal connections usually vary substantially in mammalian brains (Krubitzer, 1995, 2007; Hof et al., 2000; Kaas, 2000; Elston et al., 2001; DeFelipe et al., 2002; Elston, 2002; Harrison et al., 2002; Krubitzer and Kaas, 2005; Manger, 2005; Roth and Dicke, 2005; Herculano-Houzel et al., 2007; Sarko et al., 2009; Herculano-Houzel, 2011; Homman-Ludiye and Bourne, 2014; Dicke and Roth, 2016). Comparisons of detailed neuroanatomy would thus contribute considerably to our understanding of the evolution of the mammalian brain (DeFelipe et al., 2002; Elston, 2007; Herculano-Houzel et al., 2007; Dechmann and Safi, 2009; Sarko et al., 2009; Kern et al., 2011).

Apart from the above mentioned factors, which have an immediate effect on the information processing capacities, the ecological niche of a given species is often reflected in the morphological specification of the brain and slight differences in its structure reflect a variety of eco-ethological adaptations (Stephan et al., 1988; Voogd et al., 1998; Oelschläger, 2008). Nevertheless, a number of studies described critical biological factors influencing relative mass of the brain and the EQ, respectively (Barton and Dunbar, 1997; Dunbar, 1998, 2003, 2009; Changizi, 2003; Lefebvre et al., 2004, 2013; Manger, 2006; Shoshani et al., 2006; Shultz and Dunbar, 2006; Dunbar and Shultz, 2007; Hart et al., 2008; Finarelli, 2009; Shultz S. and Dunbar R., 2010; Navarrete et al., 2011; Boddy et al., 2012; Fitzpatrick et al., 2012; McNally et al., 2012; Arsznov and Sakai, 2013). The large body of older references regarding this topic is comprehensively discussed by van Dongen (1998). These studies focused on the volumes of whole brains (Healy and Rowe, 2007) assuming that convergent evolution shaped the whole brain of several mammalian taxa through selection arising from similar ecological requirements and natural history (de Winter and Oxnard, 2001; Kaas, 2002; Lefebvre et al., 2007; Montgomery et al., 2013; Cozzi et al., 2014). Among these factors are:

(1) Physiological parameters such as sexual maturity, life expectancy, adipose depots, and metabolism rate (including thermogenesis),

(2) Developmental parameters such as gestation period, length of neurogenetic period, nursing period, pregnancy, menopause, number, and level of physical development of the offspring,

(3) Ecological parameters such as nutrition and circadian rhythm, and

(4) Behavioral parameters such as propagation patterns, social behavior, sexual selection, and higher cognitive abilities such as learning, play behaviors, and innovation (see references above).

Comparison of the studies mentioned above revealed that each considered only a few parameters analyzed in a univariate fashion. Furthermore, these studies were restricted to few genera and species and only a minor part of these analyzed the connection of brain size and cognitive abilities. Remarkably, the recent literature has largely considered only very special parameters of cognitive abilities, e.g., tool use in primates and birds (Reader and Laland, 2002; Iwaniuk et al., 2005; Emery, 2006; Deaner et al., 2007; Lefebvre et al., 2013). Apart from that the focus has concentrated mainly on the analysis of the volume of the cerebral cortex (Barton and Dunbar, 1997; Dunbar, 1998, 2003, 2009; Voogd et al., 1998; Dunbar and Shultz, 2007; Shultz S. and Dunbar R., 2010). Other cerebral characteristics, such as the number of neurons, the intensity of cortical folding, and especially the relative sizes of distinctive parts of the brain, would have been interesting for comparative studies of brain size. However, such cerebral dimensions have currently only been analyzed for a very limited number of genera and species (Healy and Rowe, 2007; Reep et al., 2007; Herculano-Houzel, 2011).

To overcome some of the restrictions of the former studies mentioned above we compared data of a large number (115) of mammalian species (Eutheria, Placentalia) representing 14 orders; a total of up to 21 orders of Eutheria were defined so far (Storch and Asher, 2015). In contrast to most recent studies cited above, we analyzed the mass of the whole brain instead of brain parts and functional systems because these data were available in literature for a large number of species. Moreover, the measurement of the whole brain is less biased by a specialization of a single system such as hypertrophy of a single sensory system (Willemet, 2012). This paper focuses on Eutheria because only few data are available concerning the brain mass of Protheria and Metatheria species. We made use of multivariate analyses based on far-reaching literature records. The resulting metaanalysis showed which biological parameters, independent of any systematic considerations, may be correlated with a large $\mathrm{AB}$, a large $\mathrm{RB}$, as well as a large $\mathrm{EQ}$. 


\section{MATERIALS AND METHODS Species and Parameters}

We collected data from the literature (Stewart, 1902; Pettit, 1905; Crile and Quiring, 1940; Kozima, 1951; Jansen, 1953; Oboussier and Schliemann, 1966; Ridgway et al., 1966; Sigmund, 1968; Gihr and Pilleri, 1969; Pilleri and Busnel, 1969; Gruenberger, 1970; Pirlot and Stephan, 1970; Oboussier and Möller, 1971; Oboussier, 1972; Pilleri and Gihr, 1972; Ebinger, 1974; Sacher and Staffeldt, 1974; Harper and Maser, 1976; Meester and Setzer, 1977; Radinsky, 1978, 1981; Kamiya and Pirlot, 1980; Osborne and Sundsten, 1981; Ridgway, 1981; Hofman, 1982; Nowak and Paradiso, 1983; Schwerdtfeger et al., 1984; Gittleman, 1986; Stephan et al., 1988; Eisenberg, 1989; Puschmann, 1989; Tarpley and Ridgway, 1994; Gingerich, 1998; Dahlheim and Ridgway, 1999; Marino et al., 2000; Perrin et al., 2002; Wilson and Reeder, 2005; Wund and Myers, 2011) concerning the brain and body masses of 1180 adult Eutheria grouped in 115 species of 14 orders (Storch and Asher, 2015) (the monophyletic taxon Cetartiodactyla was divided into its former groups Artiodactyla and Cetacea due to their different annidations; Frey et al., 2015; Huggenberger and Klima, 2015): (1.) Artiodactyla (21 species), (2.) Carnivora (24 species), (3.) Cetacea (9 species), (4.) Chiroptera (4 species), (5.) Hyracoidea (2 species), (6.) Lagomorpha (2 species), (7.) Lipotyphla (1 species), (8.) Macroscelidae (2 species), (9.) Perissodactyla (5 species), (10.) Primates (17 species), (11.) Proboscidea (2 species), (12.) Rodentia (19 species), (13.) Scandentia (3 species), (14.) Xenarthra (4 species). The selection of species depended on the availability of brain masses and biological data (Figure 1; see Table S1). For this reason not every order is represented with an equal number of species. Data of $\mathrm{AB}$ and $\mathrm{BM}$ were taken only when both values were from the same individual. The statistical means of $\mathrm{AB}$ and $\mathrm{BM}$ were calculated when data from more than one individual were available in literature. The original data taken from the literature were not further corrected for potential inaccuracies such as fixation artifacts or differences in the usage of equations for body mass calculations of large mammals.

The relative brain mass $(\mathrm{RB})$ was calculated as the quotient from absolute brain mass $(\mathrm{AB})$ and body mass (BM) (van Dongen, 1998).

The data for $\mathrm{AB}$ and $\mathrm{BM}$ show a logarithmical relationship, which can be depicted in the following equation:

$$
\log (\mathrm{AB})=\alpha * \log (\mathrm{BM})+\log (\mathrm{k})
$$

where $\alpha$ is the slope of the regression line and $\mathrm{k}$ its intercept.

With this power function the encephalization quotient (EQ) of every species was calculated:

$$
\mathrm{EQ}=\mathrm{E}_{\mathrm{t}} / \mathrm{E}_{\mathrm{e}}
$$

where $E_{t}$ is the actual brain mass and $E_{e}$ is the expected brain mass according to the power function (Voogd et al., 1998).

Additionally, the following biological parameters were taken from literature (see above): (1.) sexual maturity in days; (2.)




maximum lifespan in years; (3.) gestation period in days; (4.) nursing period in days; (5.) litter size; (6.) frequency of pregnancies (pregnancies per year); (7.) period of postnatal eye opening in days (eye opening); (8.) group size; (9.) mean number of female sexual partners during a 10 years period (female partners); and (10.) mean number of male sexual partners during a 10 years period (male partners); (11.) percentage of raw protein in dry mass of nutrition (protein; Table 1); (12.) percentage of raw fibers in dry mass of nutrition (fiber; Table 1); and (13.) activity period in hours during daytime (circadian activity).

In order to compare all 13 biological parameters with the same multivariate statistical procedure, all variables were converted to a metric system. For this purpose, masses were specified in grams, temporal data in days and the frequency of pregnancies in births per year as well as in offspring per litter. To analyze the factor of maximum lifespan, data from the wild and from zoos were combined and the mean value was used. If only one value was available, either the wild or zoo keeping was taken into account. Average values were calculated from the sexual maturity ages of males and females. Group size (in the case of herds: the group size of recorded close social contact) was included as a numeric value to represent a proxy of social structures (Nowak and Paradiso, 1983; Wund and Myers, 2011).

For a numerical consideration, ten different food types were defined by the percentage of dry matter of singular nutrients (Table 1). Nutrient percentages were derived from available literature (Puschmann, 1989; Subcommittee on Laboratory Animal Nutrition Committee on Animal Nutrition Board on Agriculture National Research Council, 1995; Committee on Animal Nutrition Ad Hoc Committee on Nonhuman Primate Nutrition National Research Council, 2003; Dillizer, 2009). Values for facultative carnivores (e.g., Canidae, which consume a minimal percentage of vegetable food) and

TABLE 1 | Definition of nutrient values for food types (see Table S1) of Eutheria mentioned in this study (Puschmann, 1989; Subcommittee on Laboratory Animal Nutrition Committee on Animal Nutrition Board on Agriculture National Research Council, 1995; Committee on Animal Nutrition Ad Hoc Committee on Nonhuman Primate Nutrition National Research Council, 2003; Dillizer, 2009).

\begin{tabular}{lccccc}
\hline Food type & $\begin{array}{c}\text { (Raw) } \\
\text { protein }\end{array}$ & $\begin{array}{c}\text { Raw } \\
\text { fat }\end{array}$ & $\begin{array}{c}\text { (Raw) } \\
\text { fiber }\end{array}$ & $\begin{array}{c}\text { Carbon- } \\
\text { hydrates }\end{array}$ & Raw ash \\
\hline 1- Mere carnivore & 60 & 20 & 1 & 1 & 18 \\
2 - Piscivore & 61.3 & 2.6 & 0.3 & 1 & 22 \\
3 - Misc. carnivore & 40 & 5 & 3.5 & 50 & 1.5 \\
4- Omnivore & 20 & 9.5 & 32 & 8.6 & 10 \\
5 - Insectivore & 48.7 & 7.5 & 5.3 & 1 & 17.1 \\
6 - Folivore & 13 & 3.5 & 55 & 10 & 10.5 \\
7 - Graminivore & 11 & 1.9 & 29.3 & 28.3 & 6.6 \\
8 - Foli- \& graminivore & 12 & 2.7 & 42.2 & 19.2 & 8.6 \\
9 - Frugivore & 7.5 & 5 & 40 & 15 & 2.5 \\
10 - Herbivore & 14.7 & 3.5 & 18 & 4.9 & 5.6 \\
\hline
\end{tabular}

Nutrient values are defined in percent of dry matter. Two carnivorous types were set apart from each other: mere carnivores relating to the family of Felidae and miscellaneous carnivores are Canidae, as well as Thalarctos maritimus and Taxidea taxus among others (see Table S1). herbivores were oriented toward the specifications given for zoo animals and by the animal-feed industry (http://futter. wildvogelpflege.de; http://www.grau-gmbh.de; http://www.jrfarm.de/; http://www.hundeland.de/) (Table 1). Accordingly, these types of nutrition were used for quantitative comparisons and do not represent measured values of food intake of the respective species in the wild. However, this metric classification enabled us to draw general conclusions concerning food intake of the respective eutherian species.

The types of circadian activity were allocated to numeric values which represent the estimated number of hours per day that an animal is potentially active in broad daylight of a standardized $12 \mathrm{~h}$ daytime day (Nowak and Paradiso, 1983; Wund and Myers, 2011). For diurnal Eutheria, the circadian activity was determined by $12 \mathrm{~h}$, crepuscular animals are $\sim 3 \mathrm{~h}$ active, crepuscular to nocturnal animals only $1 \mathrm{~h}$, and nocturnal Eutheria are not active during daytime $(0 \mathrm{~h})$. In some species, the "activity differed" because they may adjust their day or night time activity to the corresponding habitat or food resources. Here, $6 \mathrm{~h}$ of circadian activity was arbitrarily assigned.

To depict the mating system of the Eutheria numerically, the number of possible different male and female sexual partners per 10 pregnancies was calculated. In this way we could differentiate between monogamy and polygamy of seasonal mating systems: A monogamous male animal would only have one sexual partner during these ten mating times, a seasonally mating animal, 10 possible partners, a polygynously reproducing mammal, a number of partners equaling the size of a harem. A polygynandric animal would have as many female sexual partners as are available within the group. Concerning male sexual partners, the number within the harem goes down to one, while the number of partners in the other mating systems equals the number of female mating partners. The individual specifications of mating partners are described in Table S1.

\section{Cluster Analysis of Brain Parameters}

For the cluster analysis the brain parameters $A B, R B$, and $E Q$ were normalized (quotients from the respective single values and the corresponding peak value). To check for potential correlations between these brain parameters the correlation factor after Pearson was calculated using Excel 2013 (Microsoft Corporation, Redmond, Washington, DC, U.S.A.). Then the clusters were created based on the conservative Ward-method using SPSS 19.0 (IBM Corporation, Armonk, NY, U.S.A.), since it is regarded a reliable fusion algorithm and because it forms groups of relatively equal size (Backhaus et al., 2008). As a means of specifying the distance dimension the squared Euclidean distance was chosen.

We selected final clusters (groups) after compiling a dendrogram. The selection of the number of these groups was based on the facts that: (1) the fusion distances for the compiling of the clusters were relatively high concerning a higher number of groups; and (2) groups were not comprised of only one species. Those could not have been analyzed in the following discriminant analysis. For a graphic differentiation of the groups their mean values of the standardized group parameters $A B, R B$, and $E Q$ were depicted with their corresponding standard deviation. To validate for robustness of the cluster analysis a discriminant 
analysis of the final clusters were performed using the Wilks' Lambda-method SPSS 19.0.

\section{Discriminant Analysis of the Biological Parameters}

The discriminant analysis is the central statistic procedure of this study. Using the Wilks' Lambda-method of SPSS 19.0, we analyzed how the cluster groups (see above) were separated by the various normalized biological parameters (quotients from the respective single values and the corresponding peak value). Those biological parameters which contained a discriminatory power within the discriminant function were depicted as mean values of the normalized data set.

\section{RESULTS}

\section{Relative Brain Mass and Encephalization Quotient}

The Southern flying squirrel Glaucomys volans had the highest relative brain mass (RB) found in any of the mammals in this sample with a brain making up of $3.6 \%$ of the body mass (Figure 1). The blue whale Balaenoptera musculus, in contrast, had only $0.007 \%$ and thus the smallest brain in relation to its body size. Homo sapiens had a similar RB (about 2\%) as some rodents and would, for example, be comparable in this regard to the house mouse Mus musculus whose brain makes up $1.9 \%$ of the body mass. Related groups whose body masses differed from each other also differed in their RB, a result which conforms to the expected brain and body mass allometry and its function of the regression line calculated in a double logarithmic diagram (Figure 2). The resulting power function was

$$
\mathrm{AB}=0.0951 * \mathrm{BM}^{0.688} .
$$

Using this function, the EQ of every single animal was calculated (see Table S1). For the species mentioned in the examples above, the mean EQ of the Southern flying squirrel was 1.3. The EQ of the blue whale was 0.19 and thus still the lowest EQ in this study.

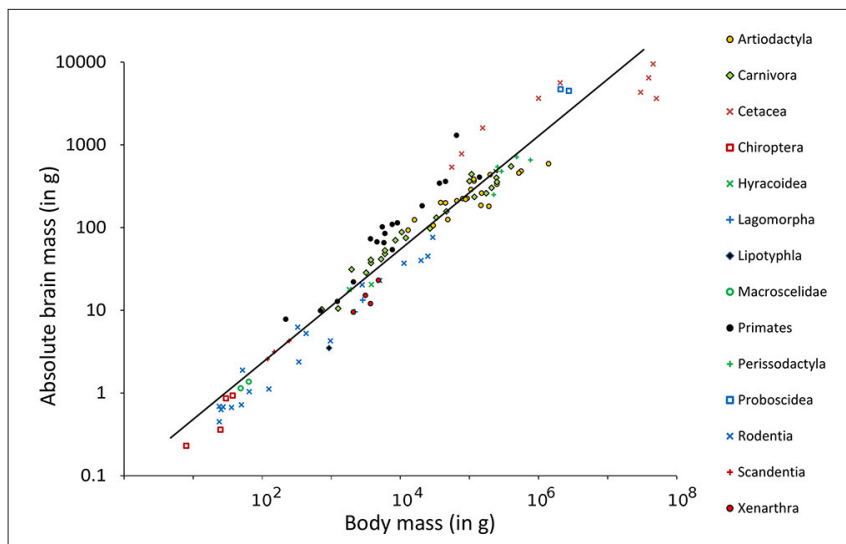

FIGURE 2 | Double logarithmic plot of absolute brain mass (AB) above body mass (BM) including regression line of 115 species of Eutheria arranged by order relationships (Figure 1).
The EQ of man was 6.68 and thus 12.6 times higher than the EQ of the house mouse (0.53) and at the same time the highest EQ of all animals in this study.

The dependency of the three brain parameters $\mathrm{AB}, \mathrm{RB}$, and $\mathrm{EQ}$ were low which was shown by the correlation factors. For the normalized parameters these factors were -0.28 for $A B$ vs. $R B$, 0.11 for $\mathrm{AB}$ vs. EQ, and 0.22 for RB vs. EQ.

\section{Cluster Analysis}

A cluster analysis was used to group all species in this metaanalysis according to their brain parameters AB, RB, and EQ. Five groups could be separated: two relatively large groups with 52 (group 1) and 35 (group 5) species, respectively; and three smaller groups with 8 (group 2), 9 (group 3), and 11 (group 4) species (Figure 1).

Group 1 contained nine orders of Euteria. Highest in number were the Artiodactyla with 19 of the 21 species (exceptions: the relatively small Indian muntjac Muntiacus muntjak and the bay duiker Cephalophus dorsalis). Moreover, there were four Xenarthra species, two Lagomorpha as well as 11 of 23 Carnivora species. The latter included Pinnipedia, Ursidae (including the herbivorous giant panda Ailuropoda melanoleuca), the leopard Panthera pardus and the tiger Panthera tigris from the family of Felidae, the wolf Canis lupus and the striped hyena Hyaena hyaena. In addition, group 1 contained 19 representatives from the group of Rodentia, including guinea pigs (Caviidae), the coypu Myocastor coypus, two species from the beaver family (Castoridae), the golden hamster Mesocricetus auratus, the brown rat Rattus norvegicus, and the crested porcupine Hystrix cristata. Group 1 also contained the European hedgehog Erinaceus europaeus from the family Insectivora (Lipotyphla), the rock hyrax Procavia capensis (Hyracoidea), and the gorilla Gorilla gorilla, which was the only primate in this group. Note that the larger species of the respective taxa were contained in group 1; e.g., the gorilla G. gorilla and the European beaver Castor fiber. The golden hamster (BM $0.125 \mathrm{~kg}, \mathrm{AB} 1.12 \mathrm{~g}$ ) and the brown rat (BM $0.34 \mathrm{~kg}, \mathrm{AB} 2.38 \mathrm{~g}$ ) were exceptions in this respect because the average $\mathrm{BM}$ in this group was $160 \pm 34 \mathrm{~kg}$, the average $\mathrm{AB}$ was $238 \pm 28 \mathrm{~g}$.

Group 2 comprised large mammals (BM $21708 \pm 8280 \mathrm{~kg}, \mathrm{AB}$ $5288 \pm 734 \mathrm{~g}$ ), the two Proboscidea and six larger representatives of the Cetacea.

In contrast to group 2, group 3 comprised representatives of four orders of relatively small mammals (BM $0.06 \pm 0.02$ $\mathrm{kg}, \mathrm{AB} 1.8 \pm 0.8 \mathrm{~g}$ ). It contained three Chiroptera species, the pygmy treeshrew Tupaia minor (Scandentia), the white-headed marmoset Callithrix geoffroyi from the primates as well as the Southern flying squirrel G. volans and the three Peromyscus species from the rodents.

Group 4 contained three representatives of new world monkeys (Platyrrhini), Cebus capucinus and the spider monkeys Ateles dariensis and A. geoffroyi, three smaller (rhesus macaque Macaca mulatta, vervet monkey Cercopithecus pygerythrus, the lar gibbon Hylobates lar), and one larger representative of the old world monkeys (Catarrhini; man H. sapiens). In addition, three smaller representatives of the Cetacea, the spotted dolphin Stenella attenuata, the bottlenose dolphin Tursiops truncatus 
and the harbor porpoise Phocoena phocoena, as well as one representative of carnivores, the kinkajou Potos flavus. The average $\mathrm{BM}$ of group 4 was $36 \pm 17 \mathrm{~kg}$, the average $\mathrm{AB}$ was $436 \pm$ $190 \mathrm{~g}$.

Group 5 contained 8 orders and many representative orders from group 1 such as the Artiodactyla with the Indian muntjac M. muntjak and the bay duiker C. dorsalis. The remaining carnivore representatives were the Canidae, the raccoon Procyon lotor, the Herpestidae (Suricata suricatta, Mungos mungo), the American badger Taxidea taxus as well as the Canada lynx Lynx canadensis and the lion Panthera leo from the family of Felidae. The Chinese hamster Cricetulus griseus, the redrumped agouti Dasyprocta aguti and the long-tailed chinchilla Chinchilla lanigera represented the family of rodents in group 5. Primates belonging to group 5 were four Platyrrhini and four Catarrhini, including the Hamadryas baboon Papio hamadryas, the Bornean orang-utan Pongo pygmaeus, and the chimpanzee Pan troglodytes. The two Elephantulus species were the only representatives of the Macroscelidae and the insect-eating Nyctalus noctula represented the only species of the Chiroptera in this group. The average $\mathrm{BM}$ of group 5 was $11 \pm 5 \mathrm{~kg}$, the $\mathrm{AB}$ $60 \pm 16 \mathrm{~g}$.

In order to characterize the groups with regard to their brain dimensions considered above, representative brains of each group are shown in scale and normalized to the same size in Figure 3. Moreover, their normalized mean values and standard deviations were compared. Figure 4A shows that group 1 was characterized by relatively low values in all three brain parameters. Group 2 had the highest $\mathrm{AB}(0.56)$, the lowest $\mathrm{RB}$ $(0.04)$, and an average EQ value. Group 3 had the lowest $A B$ $(<0.01)$, the highest $\mathrm{RB}(0.78)$, and a smaller $\mathrm{EQ}$ than group 2. Group 4 showed a mean $\mathrm{AB}$, a high $\mathrm{RB}$ and the largest $\mathrm{EQ}$ mean value (0.47). Group 5 had a low $A B$, a mean $R B$ and an EQ between groups 2 and 3. In conclusion, it is striking that, on average, groups 2, 3, and 4 each had a maximum brain parameter that set them apart from the other groups.

Accordingly, the discriminant analysis of the same three brain parameters separated these five clusters highly significantly ( $p>0.001$; see Tables S2-S4) and the robustness of these results were verified by the fact that $92.2 \%$ of the cluster members were correctly reclassified in the discriminant analysis (see Table S5).

\section{Discriminant Analysis of the Biological Parameters}

For the discriminant analysis, the normalized biological parameters were allotted to the five groups separated by the cluster analysis. Table 2 shows how distinctly the 13 biological parameters were isolated (univariately) between the specific groups. The U-statistics (Wilks' Lambdal; Backhaus et al., 2008) revealed a significant separation $(P<0.05)$ for the variables gestation period, sexual maturity, maximum lifespan, raw protein in dry matter of nutrition (protein), frequency of pregnancies per year, litter size, and number of female sexual partners (female partners; Table 2). However, the variable gestation period proved to be the best means of separation because it had the lowest Wilks' Lambda.
Table 3 describes the criteria to evaluate the discriminant function. The column "\% of variance" shows that the importance of the fourth discriminant function with a variance share of $3.2 \%$ was essentially smaller than the third discriminant function with $10 \%$, the second with $19.6 \%$, and the first with $67.2 \%$. In this multivariate analysis, the first three functions significantly supported the separation of the groups $(P<0.05)$. For the re-classification, $67 \%$ of the originally grouped cases could be assigned to the groups they belonged to.

The standardized canonic discriminant coefficient in Table 4 shows the significance of the biological parameters within the first three discriminant functions (highest absolute value). Thus, the gestation period for functions 1 and 2, the maximum lifespan for function 1, the sexual maturity for function 2 , and the percentage of raw protein in the dry matter of nutrition (protein) for function 3 had the largest discriminatory powers. From the plot of the discriminant functions, group 2 obviously separated itself from the other groups in the first discriminant function (Figure 5A). With regard to discriminant function 2, group 4 clustered apart from the other groups (Figure 5A). Groups 1 and 3 were separable by discriminant function 3 , even if there was a relatively large overlap of data from these groups (Figure 5B). In the area of overlap the tendency of group 5 was to cluster (Figure 5B). As expected from the variance values (Table 3), the discriminant function 4 did not allow any further differentiation (Figure 5B).

In order to analyze the biological parameters that significantly separated the single groups via the discriminant analysis (U-statistics and discriminant coefficient), the normalized group mean values and their standard deviations were plotted. The Eutheria of group 2, which showed a maximum $A B$ value and a minimal RB (Proboscidea and large Cetacea), had the largest gestation period (Figure 4B), the longest maximum lifespan (Figure 4C), the latest sexual maturity (Figure 4D), mainly fed on protein-rich nutrition (Figure 4E), and had the largest pregnancy intervals (lowest numbers of pregnancies per year) as well as the smallest litter size (Figures 4 F,G).

The litter sizes in group 3 were about as small as in group 2 (Figure 4G), yet the eutherians from group 3 showed the highest numbers of pregnancies per year with a short gestation time (Figures 4B,F). These eutherians also had shorter lifespans and correspondingly reached sexually mature early (Figures 4C,D). The males from group 4 had the highest ratio of mating partners (Figure 4H). However, group 4 comprised species with similarly late sexual maturity (Figure 4D), with large pregnancy intervals, and small litter sizes (Figures $\mathbf{4 F , G}$ ) as in group 2.

The mammals in groups 1 and 5 generally had no peak values with regard to these biological parameters. It is, however, noteworthy that species in group 1 consumed the least raw protein in the dry matter of the food (Figure 4E).

\section{DISCUSSION}

\section{Data Composition}

In our data set some values are referred only to a single individual, which was the case for, e.g., the blue whale B. musculus (Jansen, 1953). However, it was shown for some mammalian groups that 

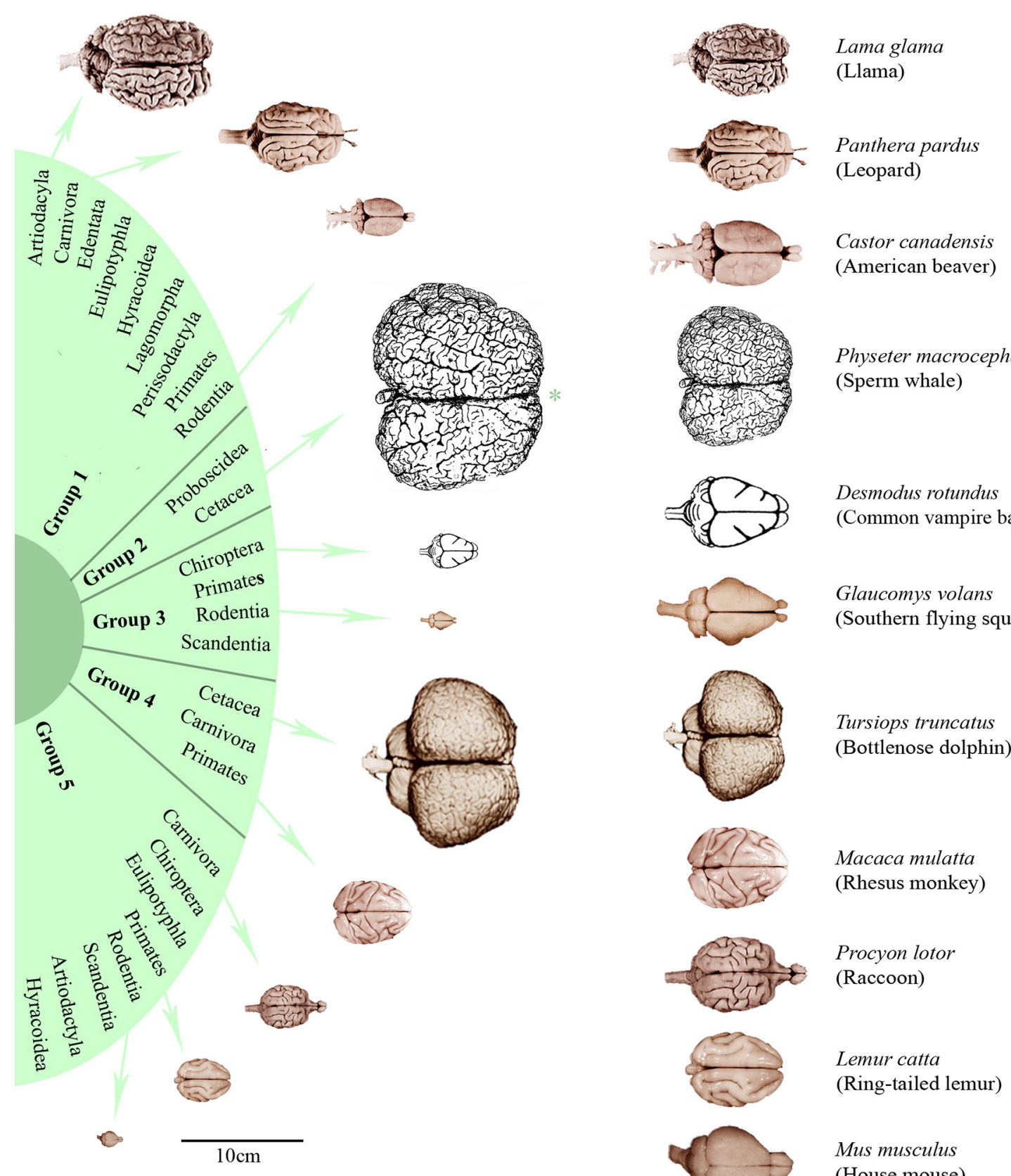

Physeter macrocephalus (Sperm whale)
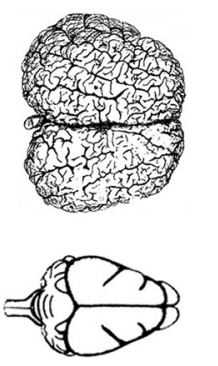

Desmodus rotundus

(Common vampire bat)

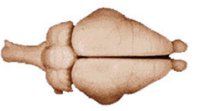

Glaucomys volans

(Southern flying squirrel)

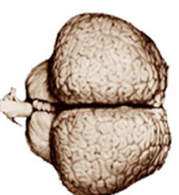

Tursiops truncatus

(Bottlenose dolphin)

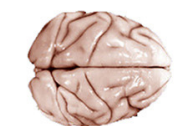

Macaca mulatta

(Rhesus monkey)

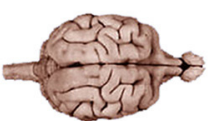

Procyon lotor

(Raccoon)

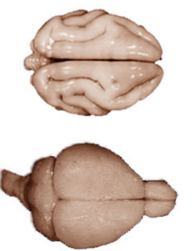

Lemur catta

(Ring-tailed lemur)

Mus musculus

(House mouse)

FIGURE 3 | Dorsal brain views of representative eutherian species arranged according to the dendrogram shown in Figure 1. On the left, the brains were aligned in scale ( ${ }^{*}$ except the sperm whale brain which is only half of its scale) and, on the right, scaled to the same total length. Brain photographs were taken from the University of Wisconsin and Michigan State Comparative Mammalian Brain Collections (www.brainmuseum.org), the sperm whale brain was depicted after Kozima (1951) and the common vampire bat brain after Baron et al. (1996).

there are high intraspecific and sex specific variations regarding brain mass and body mass (Miller and Corsellis, 1977; Baron et al., 1996; Cozzi et al., 2014; Povinelli et al., 2014). We are aware of the fact that the intraspecific variations of RB and EQ may alter our statistical results but this discussion can only be addressed when more data will be available in the future. The same holds true for the calculation of some biological parameters (e.g., activity type or dietary types). Here we developed generalized standardizations for these calculations (e.g., Table 1) because detailed data are missing for many species. Although represented by a complete matrix without missing values, our data set is restricted because some large orders, such as the Eulipotyphla, Hyracoidea, Lagomorpha, and Scandentia, are only occupied by two or three species (Figure 1). In this context, the expansion 
A

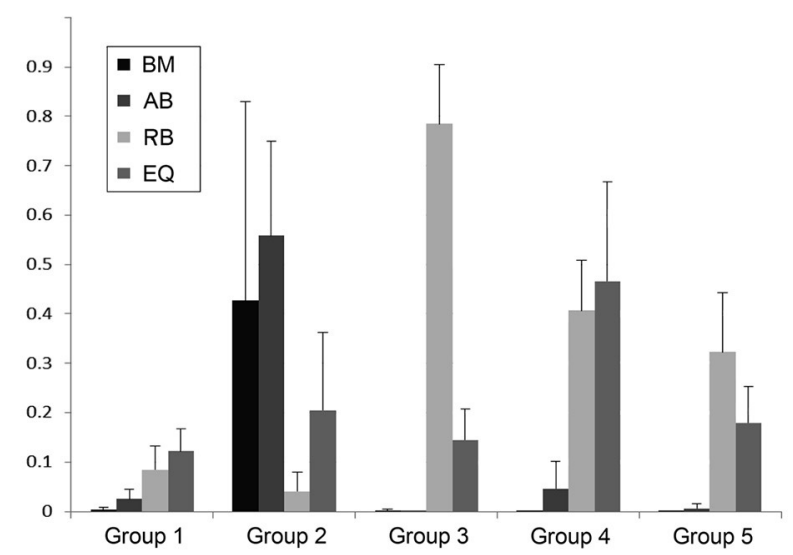

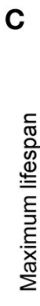

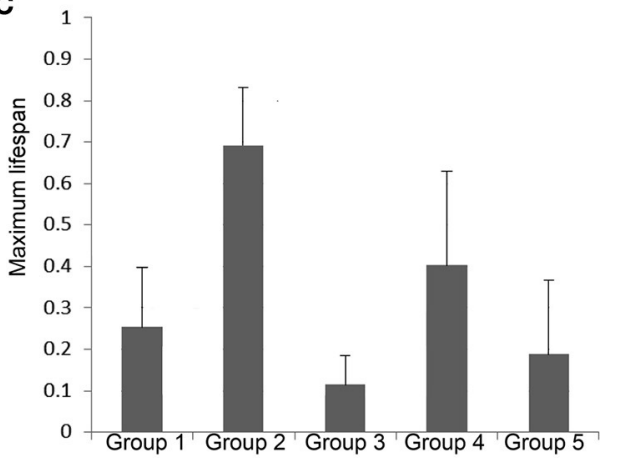

E
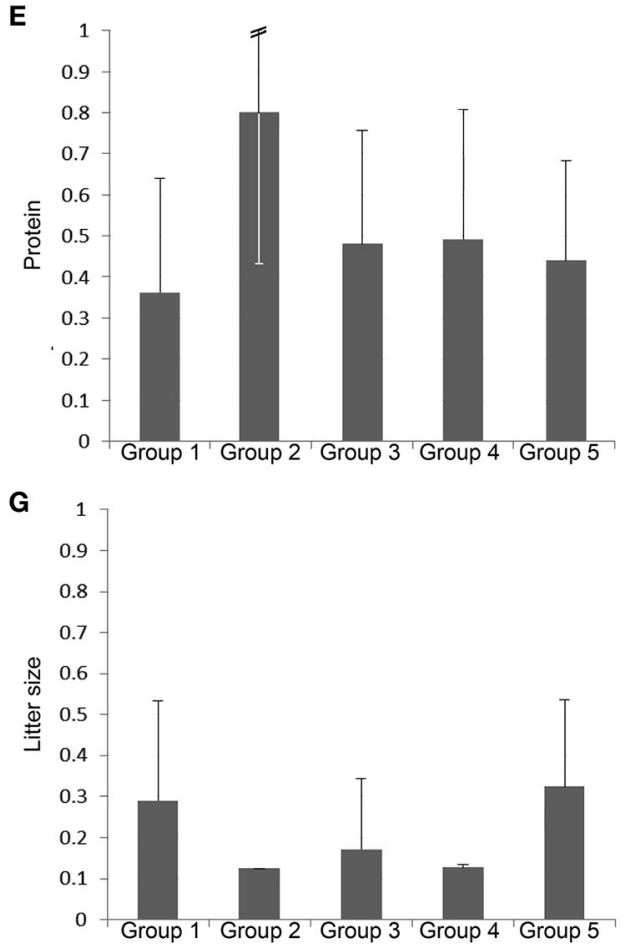

B
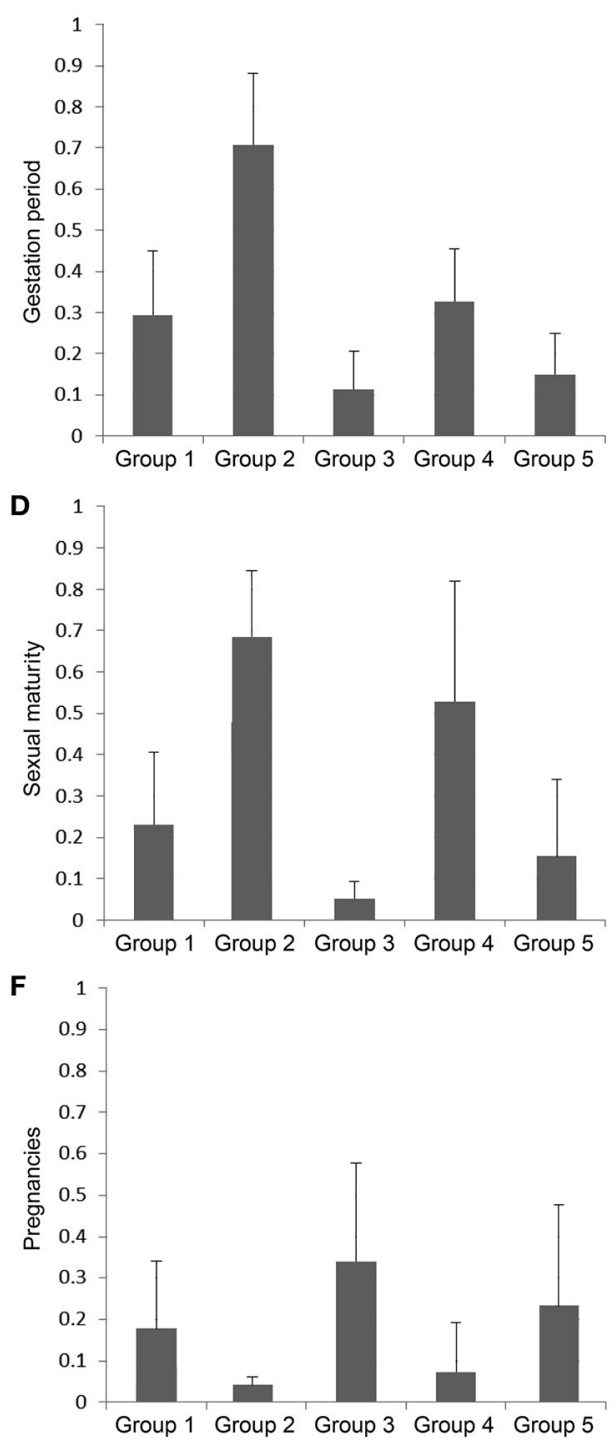

H

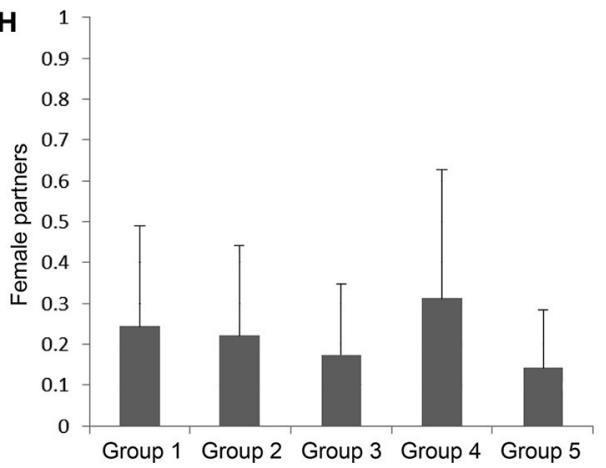

FIGURE 4 | Bar charts of normalized group mean values and standard deviations of the body mass (BM), absolute brain mass (AB), the relative brain mass (RB), and the EQ (A) as well as the biological parameters with potential discriminatory impact of the groups 1-5 defined by the cluster analysis (B-H). 
TABLE 2 | Results of the U-statistics (Wilks' Lambda-method).

\begin{tabular}{lcc}
\hline Biological parameter & Wilks' Lambda & Significance (P) \\
\hline Gestation period & 0.474 & $<0.001$ \\
Sexual maturity & 0.562 & $<0.001$ \\
Maximum lifespan & 0.588 & $<0.001$ \\
Protein & 0.864 & 0.003 \\
Pregnancies per year & 0.869 & 0.004 \\
Litter size & 0.903 & 0.023 \\
Female partners & 0.913 & 0.040 \\
Nursing period & 0.920 & 0.056 \\
Male partners & 0.927 & 0.077 \\
Circadian activity & 0.931 & 0.093 \\
Fiber & 0.937 & 0.122 \\
Eye opening & 0.974 & 0.576 \\
Group size & 0.984 & 0.777 \\
\hline
\end{tabular}

The biological parameters were ordered according to their significance values.

TABLE 3 | Criteria to evaluate discrimant functions of biological parameters.

\begin{tabular}{lccc}
\hline Function & Eigenvalue & \% of Variance & Significance \\
\hline 1 & 1.900 & 67.2 & 0.000 \\
2 & 0.553 & 19.6 & 0.000 \\
3 & 0.283 & 10.0 & 0.035 \\
4 & 0.092 & 3.2 & 0.513 \\
\hline
\end{tabular}

The discriminant functions 1-3 contribute significantly to the separation of the groups $(p<0.05)$. The column "\% of Variance" shows that the impact of the discriminant function 4 is essentially less than the other functions.

TABLE 4 | Standardized canonic discriminant function coefficient for the significant discriminant functions 1-3 (Table 3 ) of the biological parameters.

\begin{tabular}{lccc}
\hline Biological parameter & Function 1 & Function 2 & Function 3 \\
\hline Gestation period & $0.994^{\star}$ & $0.732^{*}$ & -0.437 \\
Maximum lifespan & $0.577^{\star}$ & 0.439 & $0.755^{\star}$ \\
Litter size & 0.378 & 0.328 & -0.482 \\
Protein & 0.259 & -0.049 & $0.984^{\star}$ \\
Pregnancies per year & 0.098 & 0.233 & 0.521 \\
Female partners & 0.064 & 0.291 & -0.727 \\
Eye opening & 0.053 & 0.418 & -0.047 \\
Sexual maturity & 0.004 & $-1.371^{*}$ & -0.375 \\
Group size & -0.03 & -0.033 & 0.292 \\
Fiber & -0.141 & -0.32 & 0.35 \\
Male partners & -0.161 & -0.692 & 0.22 \\
Circadian activity & -0.185 & -0.328 & -0.221 \\
Nursing period & -0.442 & 0.418 & 0.211 \\
\hline
\end{tabular}

The two maximum absolute values of each function were marked with an asterisk.

of database projects like PanTHERIA (Jones et al., 2009) would bring substantial new input into this genre of brain size studies.

Note that we analyzed separately various Eutheria species and did not take into account the phylogenetic origin and specialized

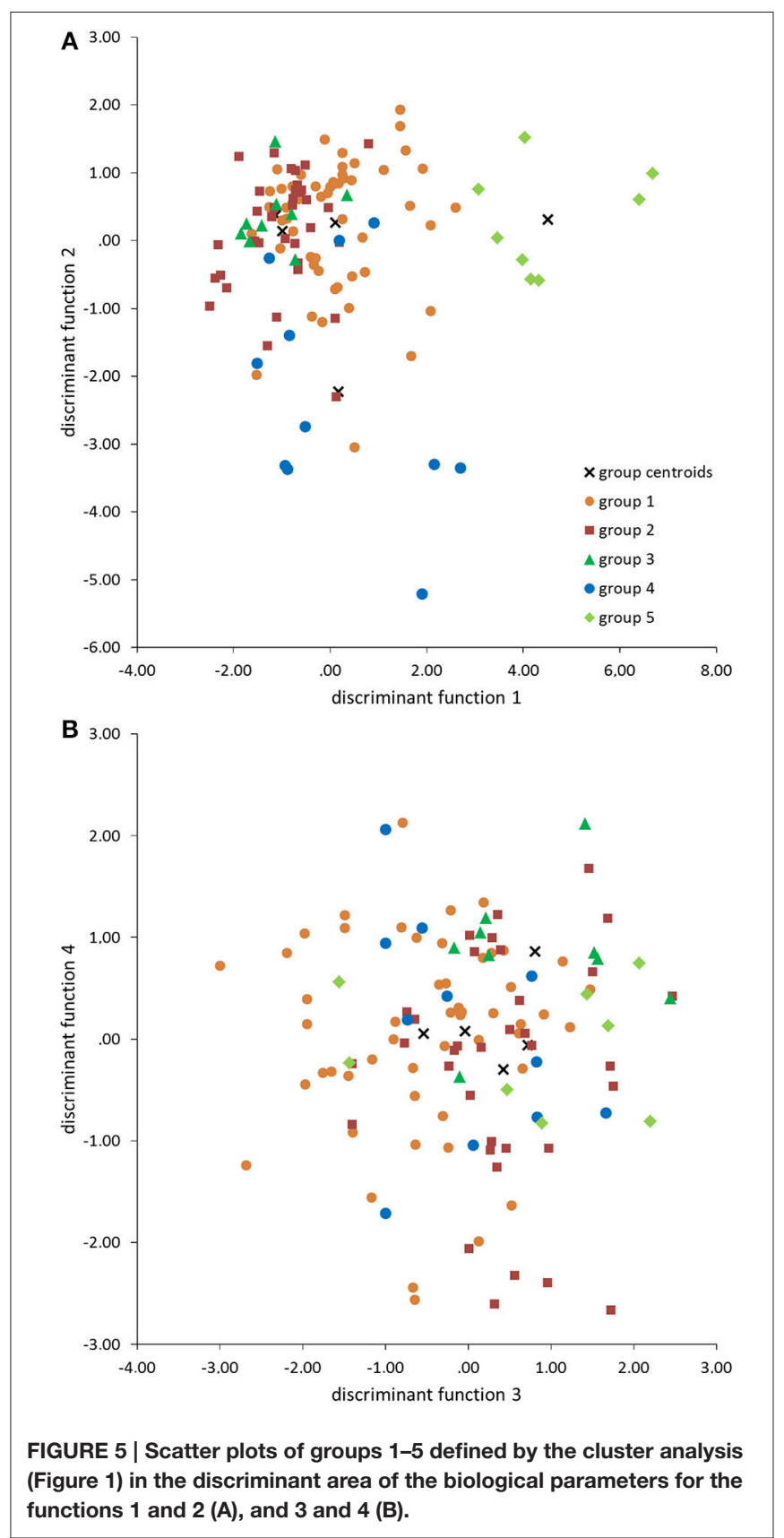

adaptations, like echolocation or electroperception, in our statistical analysis. Here, comparisons of whole brain parameters $(\mathrm{AB}, \mathrm{RB}, \mathrm{EQ})$ as a principle seems to be more appropriate than the comparison of selected ones such as brain regions, rhombomeres, circuits, or neuron types, which may show taxaspecific allometric relationships (Willemet, 2012). In this way, we avoided a separation of specific taxa with hypertrophic and rudimentary brain structures such as olfactory, auditory, visual or other parts of the brain. For instance, odontocetes have extended auditory nuclei, but no primary olfactory brain structures and small hippocampi, while primates have relatively large hippocampal structures and relatively smaller auditory 
nuclei (Oelschläger, 2008; Oelschläger et al., 2010; Shultz S. and Dunbar R. I. M., 2010).

Among parameters that could not be considered, the occurrence of menopause might be an interesting feature. However, only a few mammals live beyond their reproductive phase. Menopause had only been verified for two large dolphins (Globicephala macrorhynchus, Orcinus orca) and three primate species (G. gorilla, Pan troglodytes, H. sapiens; Johnstone and Cant, 2010). Even though menopause was not taken into account because it is so rare, it is striking to see that these species generally possess a large brain (Figures 2, 3). Hibernation was not included in the analysis for the same reason: among the 115 mammals examined, only two hibernate (E. europaeus and Plecotus auritus) and another two have periods of dormancy (Ursus arctos and Thalarctos maritimus; Puschmann, 1989).

\section{Brain Size and the Phylogenetic Tree}

The results of the cluster analysis show that, concerning the brain parameters $\mathrm{AB}, \mathrm{RB}$, and $\mathrm{EQ}$, each group (cluster) includes Eutheria from phylogenetically distantly related taxa. Hence the whole brain parameters can be interpreted independently of the phylogenetic tree.

Interpreting the consequences of $\mathrm{AB}$ and $\mathrm{RB}$ differences in the respective orders, Stephan et al. (1988) described a secondary decrease or increase of the body mass along with a constant brain size and coined the terms dwarfism and giantism for closely related species. The phylogeny of the Equidae was discussed as an example of the increase of the body mass and a decreased $\mathrm{RB}$, which largely aligns with the nutrition change from fruit and leaves to grass (Nowak and Paradiso, 1983; Wund and Myers, 2011). Cetacea also have disproportionally large body mass relative to brain mass, which might be explained by the modified gravitational forces in the aquatic habitat (Marino, 1998). Moreover, odontocetes as well as anthropoid primates have a greater variance in $\mathrm{EQ}$, suggesting that evolutionary constraints resulting in a strict correlation between brain and body mass had become relaxed (Boddy et al., 2012; Montgomery et al., 2013). As a result, for some mammalian groups body mass appeared to be an inadequate reference value for the comparison of ungulates, marine mammals, and primates to other mammals (Radinsky, 1978; Manger et al., 2013). In our data, this constraint was especially evident in the example of the blue whale EQ, which was comparatively small (0.19) although the AB was high $(\sim 3.6 \mathrm{~kg})$.

The primates were distributed into two separate groups (groups 4 and 5). Although their EQ values were similar to those of the old world monkeys from group 4, the fact that hominides (except man H. sapiens) were assigned to group 5 was probably due to their body mass. In this case, the RB was crucial for this classification. Because the interpretation of changes of RB and EQ is challenging when body masses change (Striedter, 2005), the use of the three measurements of brain mass (AB, RB, EQ) in parallel is more likely to discover general potential influences on brain mass. This fact is also shown by the discrete clustering of the Artiodactyla (groups 1 and 5) and Cetacea (groups 2 and 4) which belong to the same order Cetartiodactyla (Frey et al., 2015; Huggenberger and Klima, 2015).

\section{Brain Size and Critical Biological Parameters}

The analyses of the various biological parameters for the five groups with the cluster analysis can be summarized as follows. The Eutheria with high $\mathrm{AB}$ in group 2 have long and rare pregnancies with small litter sizes, a late sexual maturity but long lifespans; they feed on protein-rich nutrition (Figures 4, 6). Animals with high RB such as Eutheria of group 3 have short and frequent gestation periods, an early sexual maturity, and a short lifespan. Additionally, males of group 3 have only few potential sexual partners (Figures 4, 6), whereas a high number of potential sexual partners is related to high EQs. Moreover, Eutheria with high EQ (group 4) show late sexual maturity and rare gestations with small litter sizes (Figures 4, 6).

Group 4, which was distinguished by a significantly high $\mathrm{EQ}$, is comprised of three representatives from the group of new world monkeys: the white-headed capuchin C. capucinus that exhibits the ability of tool use and the spider monkeys A. dariensis and A. geoffroyi that use their tails to grab branches (Wilson and Reeder, 2005). Group 4 also includes three smaller representatives from the group of old world monkeys: the lar gibbon Hylobates lar, whose abilities to climb even exceeds those of a spider monkey (Nowak and Paradiso, 1983) and a larger representative from the group of old world monkeys, man $H$. sapiens, with the largest EQ. Interestingly, one predator, the kinkajou P. flavus from the family of Procyonidae, was also assigned to group 4. In this context it is also remarkable that, in contrast to the other Procyonidae, the ability of the kinkajou to climb using his tail to grab branches resulted in its accidental assignment to the group of lemurs when first described in 1774 (Nowak and Paradiso, 1983; Wund and Myers, 2011).

Former studies demonstrated that mammals with long gestation periods and long lifespans had large relative brain masses and EQs, respectively (Sacher and Staffeldt, 1974; Hofman, 1993). For instance, brain mass seemingly depended on the maternal energy available during gestation (Martin, 1981; Marino, 1998). In this study, only group 2, which was characterized by a significantly high $A B$, was separated in the

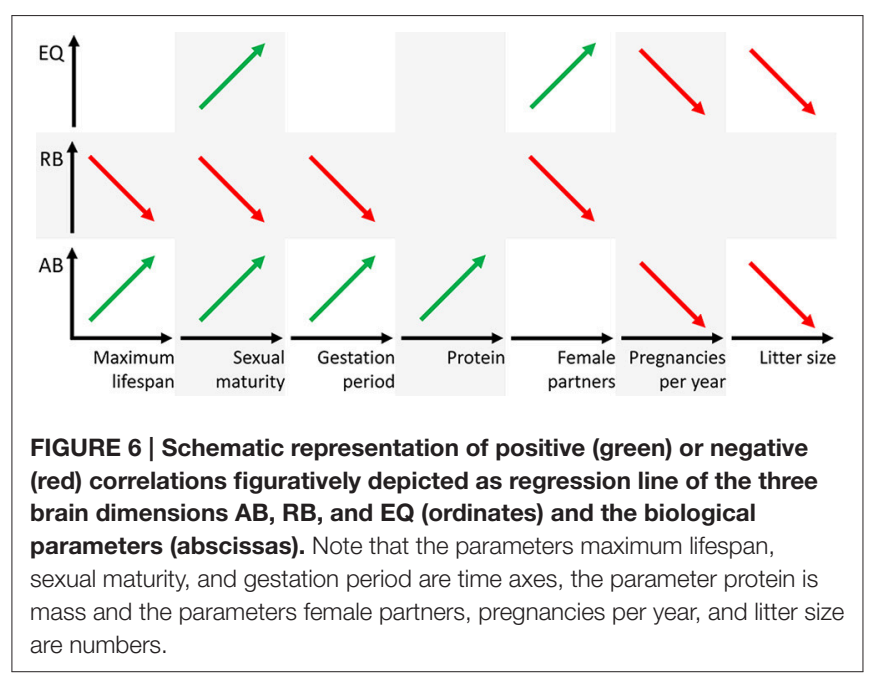


discriminate analysis from the other groups on the basis of the gestation period. However, the average gestation period of group 2 must, apart from the brain size, also be considered in connection with other factors, such as BM, which in group 2 is above average (Figure 4A). On the one hand, another potentially important factor is that all representatives from group 2 are precocial (see Table S1). On the other hand, group 4, in which are also precocial mammals (except the kinkajou $P$. flavus), is similar to group 1 with regard to gestation periods, (Figure 4B). This pattern probably results from the fact that group 1 is comprised of a large number of Artiodactyla, which are precocial and have therefore the need of extended gestation periods (in comparison to groups 3 and 5) but low $A B, R B$, and EQ (Figure 4A). This may be why the gestation period was not a criterion to separate group 1 from the others in the course of the discriminant analysis. In our discriminant analysis, the frequency of pregnancies still reveals a tendency of an inverse correlation with the gestation periods (Figures 4B,F). The precocial Euteria from groups 2 and 4 (with relatively long gestation periods) were less often pregnant than representatives from group 3, which had short gestation periods and, apart from white-headed marmoset, was comprised of altricial animals. Up to now no correlations between the frequency of pregnancies or litter size (highest in groups 1 and 5; Figures 4F,G) and the brain mass of mammals had been observed. Gittleman (1986) for instance examined the brain size of carnivores with regard to litter size, but found no correlation. The author Gittleman (1986) pointed out that the different brain sizes between carnivores and insectivores might reflect the different complexities of their hunting strategies. While insectivores have to master smaller distances to find their prey and pick them with a relatively high success rate, carnivores must acquire complex hunting abilities and experience a comparably low success rate.

As mentioned above, differences in the biological parameters do not provide a robust explanation for the separation of groups 1 and 5 (cf. Figure 4). However, it was striking that group 5, whose representatives were predominantly omnivores or carnivores, also contained the Indian muntjac M. muntjak and the bay duiker $C$. dorsalis from the artiodactyls. In comparison to the artiodactyls from group 1 these animals show special features concerning their diet (see Table S1). The Indian muntjac feed on various kinds of plants, especially fruit, while the artiodactyls of group 1 were exclusively specialized on leaves and/or grass. Accordingly, the differences of brain parameters in groups 1 and 5 may reflect dietary differences that were not evident in our data. Only group 2 was separated from the other groups by the percentage of raw protein in the diet, but this parameter was not the sole factor for this separation.

It is generally plausible that various biological parameters may have co-evolved because they had been linked selection parameters. For example, selection favoring investment in a large number of offspring (r-selection) was shown to be correlated with small body size. Alternatively, K-selection (selection favoring investment in a small number of offspring to increase their fitness) promotes large body size, long lifespans, small litter sizes, and fewer descendants during lifetime (Pianka, 1970; van Dongen, 1998). Although these selection types ( $\mathrm{r}-$ and Kselections) should be relevant for brain evolution (van Dongen, 1998) there is no distinct correlation to brain size and therefore interpretations are contradicting. Selection in favor of small body size may be correlated with larger EQs in some mammals and with the reduction of the EQ in other species (van Dongen, 1998).

\section{CONCLUSION}

The brain is among the most cost-intensive organs with regard to metabolism. For this reason, a large brain has either to exhibit crucial survival benefits or it would have to surrender to selection pressure and ultimately reduce its size (Armstrong, 1982, 1983; Gibson, 1986; Aiello and Wheeler, 1995; Isler and van Schaik, 2009). Considering the statistical results from this study, it is important to note that our analyses are appropriate to correlate brain masses (AB, RB, EQ) with biological parameters such as physiology, development, ecology, and behavior. Implications of functional (cognitive) capabilities of the species were thus not possible. However, it is striking that the informative biological parameters (Figures 4, 6) can be used to define the potential trophic levels of eutherian species within their consumerresource networks (Olff et al., 2009). This is where the lowest trophic levels of, for example, herbivores and insectivores from groups 1, 3, and 5 can be found; all of these animals have relatively short gestation periods along with a high frequency of pregnancies and large litter size, short lifespan, and early sexual maturity. Animals from groups 2 and 4, omnivores, carnivores, and piscivores that, despite long lifespans, give birth to few offspring because of late sexual maturity rank on higher trophic levels (Figure 4). Thus, a large $\mathrm{AB}$ (group 2) or a high EQ (group 4) is generally found in Eutheria of higher trophic levels. Animals of lower trophic levels only have a large $\mathrm{RB}$ if they are very small (small BM) like the Eutheria from group 3 .

\section{AUTHOR CONTRIBUTIONS}

CS and LZ contributed equally as first authors. Conception of study: CS, LZ, KM, SH. Design of study: CS, LZ, MH, WW, SH. Data collection: CS, LZ, MH. Data Analysis: CS, LZ, KM. Interpretation of data: CS, LZ, MH, KM, WW, SH. Discussion of literature: CS, LZ, MH, KM, WW, SH.

\section{ACKNOWLEDGMENTS}

We thank John-Patrick Schöllgen for translation help and H. Carl Gerhardt, Natasha Moser, and Hannsjörg Schröder for numerous helpful suggestions.

\section{SUPPLEMENTARY MATERIAL}

The Supplementary Material for this article can be found online at: http://journal.frontiersin.org/article/10.3389/fnana. 2016.00091 


\section{REFERENCES}

Aiello, L. C., and Wheeler, P. (1995). The expensive-tissue hypothesis: the brain and the digestive system in human and primate evolution. Curr. Anthropol. 36, $199-221$.

Allman, J. M. (1999). Evolving Brains. New York, NY: W. H. Freeman and Co.

Armstrong, E. (1982). A look at relative brain size in mammals. Neurosci. Lett. 34, 101-104. doi: 10.1016/0304-3940(82)90159-8

Armstrong, E. (1983). Relative brain size and metabolism in mammals. Science 220, 1302-1304. doi: 10.1126/science.6407108

Arsznov, B. M., and Sakai, S. T. (2013). The procyonid social club: comparison of brain volumes in the coatimundi (Nasua nasua, N. narica), kinkajou (Potos flavus), and raccoon (Procyon lotor). Brain Behav. Evol. 82, 129-145. doi: 10.1159/000354639

Backhaus, K., Erichson, B., Plinke, W., and Weiber, R. (2008). Multivariate Analysemethoden. Berlin: Springer.

Baron, G. (2007). Comparative studies of brain size and structure volume in mammals. Comp. Primate Biol. 4, 125-135. doi: 10.1016/B0-12-3708788/00066-5

Baron, G., Stephan, H., and Frahm, H. D. (1996). Comparative Neurobiology in Chiroptera: Brain Characteristics in Functional Systems, Ecoethological Adaptation, Adaptive Radiation, and Evolution. Basel: Birkhäuser Verlag.

Barton, R. A., and Dunbar, R. I. M. (1997). "Evolution of the social brain," in Machiavellian Intelligence II: Extensions and Evaluations, eds A. Whiten and R. W. Byrne (Cambridge: University Press), 240-263.

Boddy, A. M., McGowen, M. R., Sherwood, C. C., Grossman, L. I., Goodman, M., and Wildman, D. E. (2012). Comparative analysis of encephalization in mammals reveals relaxed constraints on anthropoid primate and cetacean brain scaling. J. Evol. Biol. 25, 981-994. doi: 10.1111/j.1420-9101.2012. 02491.x

Butti, C., Sherwood, C. C., Hakeem, A. Y., Allman, J. M., and Hof, P. R. (2009). Total number and volume of Von Economo neurons in the cerebral cortex of cetaceans. J. Comp. Neurol. 515, 243-259. doi: 10.1002/cne.22055

Changizi, M. A. (2003). Relationship between number of muscles, behavioral repertoire size, and encephalization in mammals. J. Theor. Biol. 220, 157-168. doi: 10.1006/jtbi.2003.3125

Committee on Animal Nutrition Ad Hoc Committee on Nonhuman Primate Nutrition and National Research Council (2003). Nutrient Requirements of Nonhuman Primates. Washington, DC: Academic Press.

Cozzi, B., Povinelli, M., Ballarin, C., and Granato, A. (2014). The brain of the horse: weight and cephalization quotients. Brain Behav. Evol. 83, 9-16. doi: $10.1159 / 000356527$

Crile, G., and Quiring, D. P. (1940). A record of the body weight and certain organ and gland weights of 3690 animals. Ohio J. Sci. 40, 219-260.

Dahlheim, M. E., and Ridgway, S. H. (1999). "Killer whale," in The Second Book of Dolphins and the Porpoises Handbook of Marine Mammals, eds S. H. Ridgway and R. Harrison (London: Academic Press), 281-322.

Deaner, R. O., Isler, K., Burkart, J., and Schaik, C. (2007). Overall brain size, and not encephalization quotient, best predicts cognitive ability across nonhuman primates. Brain Behav. Evol. 70, 115-124. doi: 10.1159/000102973

Dechmann, D. K. N., and Safi, K. (2009). Comparative studies of brain evolution: a critical insight from the Chiroptera. Biol. Rev. 84, 161-172. doi: 10.1111/j.1469185X.2008.00067.x

DeFelipe, J., Alonso-Nanclares, L., and Arellano, J. I. (2002). Microstructure of the neocortex: comparative aspects. J. Neurocytol. 31, 299-316. doi: 10.1023/A:1024130211265

de Winter, W., and Oxnard, C. E. (2001). Evolutionary radiations and convergences in the structural organization of mammalian brains. Nature 409, 710-714. doi: $10.1038 / 35055547$

Dicke, U., and Roth, G. (2016). Neuronal factors determining high intelligence. Philos. Trans. R. Soc. B Biol. Sci. 371:20150180. doi: 10.1098/rstb.2015.0180

Dillizer, N. (2009). Ernährungsberatung in der Kleintierpraxis. München: Elsevier.

Douglas, R. J., and Martin, K. A. C. (2007). Mapping the matrix: the ways of neocortex. Neuron 56, 226-238. doi: 10.1016/j.neuron.2007.10.017

Dunbar, R. I. M. (1998). The social brain hypothesis. Anthropology 6, 178-190.

Dunbar, R. I. M. (2003). The social brain: mind, language, and society in evolutionary perspective. Annu. Rev. Anthropol. 32, 163-181. doi: 10.1146/annurev.anthro.32.061002.093158
Dunbar, R. I. M. (2009). The social brain hypothesis and its implications for social evolution. Ann. Hum. Biol. 36, 562-572. doi: 10.1080/03014460902960289

Dunbar, R. I. M., and Shultz, S. (2007). Understanding primate brain evolution. Philos. Trans. R. Soc. B Biol. Sci. 362, 649-658. doi: 10.1098/rstb.2006.2001

Ebinger, P. (1974). A cytoarchitectonic volumetric comparison of brains in wild and domestic sheep. Z. Anat. Entwicklungsgesch. 144, 267-302. doi: 10.1007/BF00522811

Eisenberg, J. F. (1989). Mammals of the Neotropics, Vol. 1, The Northern Neotropics: Panama, Colombia, Venezuela, Guyana, Suriname, French Guiana. Chicago: University Press.

Elston, G. N. (2002). Cortical heterogeneity: implications for visual processing and polysensory integration. J. Neurocytol. 31, 317-335. doi: 10.1023/A:1024182228103

Elston, G. N. (2007). "Evolution of the pyramidal cell in primates," in Evolution of Nervous Systems, ed J. Kaas (San Diego, CA: Academic Press), 191-242.

Elston, G. N., Benavides-Piccione, R., and DeFelipe, J. (2001). The pyramidal cell in cognition: a comparative study in human and monkey. J. Neurosci. 21:RC163.

Emery, N. J. (2006). Cognitive ornithology: the evolution of avian intelligence. Philos. Trans. R. Soc. B Biol. Sci. 361, 23-43. doi: 10.1098/rstb.2005.1736

Finarelli, J. A. (2009). Does encephalization correlate with life history or metabolic rate in Carnivora? Biol. Lett. 6, 350-353. doi: 10.1098/rsbl.2009.0787

Fitzpatrick, J. L., Almbro, M., Gonzalez-Voyer, A., Hamada, S., Pennington, C., Scanlan, J., et al. (2012). Sexual selection uncouples the evolution of brain and body size in pinnipeds. J. Evol. Biol. 25, 1321-1330. doi: 10.1111/j.14209101.2012.02520.x

Frey, R., Hindrichs, H., and Zachos, F. E. (2015). "Artiodactyla, Paarhufer inkl Wale," in Spezielle Zoologie, eds W. Westheide and G. Rieger (Heidelberg: Spektrum Akademischer Verlag), 575-599.

Gibson, K. R. (1986). "Cognition, brain size and the extraction of embedded food resources," in Primate Ontogeny, Cognition and Social Behaviour, eds J. G. Else and P. C. Lee (Cambridge: University Press), 93-104.

Gihr, M., and Pilleri, G. (1969). "Hirn-Körpergewichts-Beziehungen bei Cetaceen," in Investigations on Cetacea, ed G. Pilleri (Bern: Institute of Brain Anatomy), 109-126.

Gingerich, P. D. (1998). "Palaeobiological perspectives on Mesonychia, Archaeoceti and the origin of whales," in The Emergence of Whales, ed J. G. M. Thewissen (New York, NY: Plenum Press), 281-322.

Gittleman, J. L. (1986). Carnivore brain size, behavioral ecology, and phylogeny. J. Mammal. 67, 23-36. doi: 10.2307/1380998

Glickstein, M., Oberdick, J., and Voogd, J. (2007). "Evolution of the Cerebellum," in Evolution of Nervous Systems, ed J. H. Kaas (Oxford: Academic Press), 413-442. Available online at: http://www.sciencedirect.com/science/article/pii/ B0123708788000859 (Accessed September 2, 2015).

Gruenberger, H. B. (1970). "On the cerebral anatomy of the amazon dolphin (Inia geoffrensis)," in Investigations on Cetacea, ed G. Pilleri (Bern: Institute of Brain Anatomy), 129-146.

Harper, J. W., and Maser, J. D. (1976). A macroscopic study of the brain of (Bison bison), the American Plains Buffalo. Anat. Rec. 184, 187-202. doi: 10.1002/ar.1091840206

Harrison, K. H., Hof, P. R., and Wang, S. S.-H. (2002). Scaling laws in the mammalian neocortex: does form provide clues to function? J. Neurocytol. 31, 289-298. doi: 10.1023/A:1024178127195

Hart, B. L., Hart, L. A., and Pinter-Wollman, N. (2008). Large brains and cognition: where do elephants fit in? Neurosci. Biobehav. Rev. 32, 86-98. doi: 10.1016/j.neubiorev.2007.05.012

Harvey, P. H., Clutton-Brock, T. H., and Mace, G. M. (1980). Brain size and ecology in small mammals and primates. Proc. Natl. Acad. Sci. U.S.A. 77, 4387-4389.

Haug, H. (1987). Brain sizes, surfaces, and neuronal sizes of the cortex cerebri: a stereological investigation of man and his variability and a comparison with some mammals (primates, whales, marsupials, insectivores, and one elephant). Am. J. Anat. 180, 126-142. doi: 10.1002/aja.1001800203

Healy, S. D., and Rowe, C. (2007). A critique of comparative studies of brain size. Proc. R. Soc. B Biol. Sci. 274, 453-464. doi: 10.1098/rspb.2006.3748

Herculano-Houzel, S. (2011). Not all brains are made the same: new views on brain scaling in evolution. Brain Behav. Evol. 78, 22-36. doi: 10.1159/000327318

Herculano-Houzel, S., Mota, B., and Lent, R. (2007). How to build a bigger brain: cellular scaling rules for rodent brains. Proc. Natl. Acad. Sci. U.S.A. 103, 2138-2143. doi: 10.1016/B0-12-370878-8/00345-1 
Hofman, M. A. (1982). Encephalization in mammals in relation to the size of the cerebral cortex. Brain Behav. Evol. 20, 84-96. doi: 10.1159/000121583

Hofman, M. A. (1993). Encephalization and the evolution of longevity in mammals. J. Evol. Biol. 6, 209-227.

Hof, P. R., Glezer, I. I., Nimchinsky, E. A., and Erwin, J. M. (2000). Neurochemical and cellular specializations in the mammalian neocortex reflect phylogenetic relationships: evidence from primates, cetaceans, and artiodactyls. Brain Behav. Evol. 55, 300-310.

Homman-Ludiye, J., and Bourne, J. A. (2014). Mapping arealisation of the visual cortex of non-primate species: lessons for development and evolution. Front. Neural Circuits 8:79. doi: 10.3389/fncir.2014.00079

Huggenberger, S., and Klima, M. (2015). "Cetacea, Waltiere," in Spezielle Zoologie, eds W. Westheide and G. Rieger (Heidelberg: Spektrum Akademischer Verlag), 600-613.

Isler, K., and van Schaik, C. P. (2009). The expensive brain: a framework for explaining evolutionary changes in brain size. J. Hum. Evol. 57, 392-400. doi: 10.1016/j.jhevol.2009.04.009

Iwaniuk, A. N., Dean, K. M., and Nelson, J. E. (2005). Interspecific allometry of the brain and brain regions in parrots (Psittaciformes): comparisons with other birds and primates. Brain Behav. Evol. 65, 40-59. doi: 10.1159/000081110

Jansen, J. (1953). Studies on the Cetacean Brain: the Gross Anatomy of the Rhombencephalon of the Fin Whale (Balaenoptera physalus, L.). Hvelradets Skrifter (Norske Videnskaps-Akademi i Oslo) 37, 1-37.

Jerison, H. J. (1973). Evolution of the Brain and Intelligence. New York, NY: Academic Press.

Johnstone, R. A., and Cant, M. A. (2010). The evolution of menopause in cetaceans and humans: the role of demography. Proc. R. Soc. B Biol. Sci. 277, 3765-3771. doi: 10.1098/rspb.2010.0988

Jones, K. E., Bielby, J., Cardillo, M., Fritz, S. A., O'Dell, J., Orme, C. D. L., et al. (2009). PanTHERIA: a species-level database of life history, ecology, and geography of extant and recently extinct mammals: ecological archives E090-184. Ecology 90, 2648-2648. doi: 10.1890/08-1494.1

Kaas, J. (2002). Convergences in the modular and areal organization of the forebrain of mammals: implications for the reconstruction of forebrain evolution. Brain Behav. Evol. 59, 262-272. doi: 10.1159/000063563

Kaas, J. H. (2000). Why is brain size so important: design problems and solutions as neocortex gets better or smaller. Brain Mind 1, 7-23. doi: 10.1023/A:1010028405318

Kamiya, T., and Pirlot, P. (1980). Brain organization in (Platanista gangetica). Sci. Rep. Whales Res. Inst. Tokyo 32, 105-126.

Kern, A., Siebert, U., Cozzi, B., Hof, P. R., and Oelschläger, H. H. A. (2011). Stereology of the neocortex in Odontocetes: qualitative, quantitative, and functional implications. Brain Behav. Evol. 77, 79-90. doi: 10.1159/000323674

Kozima, T. (1951). On the brain of the sperm whale. Sci. Rep. Whales Res. Inst. Tokyo 6, 49-72.

Krubitzer, L. (1995). The organization of neocortex in mammals: are species differences really so different? Trends Neurosci. 18, 408-417.

Krubitzer, L. (2007). The magnificent compromise: cortical field evolution in mammals. Neuron 56, 201-208. doi: 10.1016/j.neuron.2007.10.002

Krubitzer, L., and Kaas, J. (2005). The evolution of the neocortex in mammals: how is phenotypic diversity generated? Curr. Opin. Neurobiol. 15, 444-453. doi: 10.1016/j.conb.2005.07.003

Lefebvre, L., Reader, S. M., and Boire, D. (2007). "The evolution of encephalization," in Evolution of Nervous Systems, ed J. Kaas (San Diego, CA: Academic Press), 121-141.

Lefebvre, L., Reader, S. M., and Sol, D. (2004). Brains, innovations and evolution in birds and primates. Brain Behav. Evol. 63, 233-246. doi: 10.1159/000076784

Lefebvre, L., Reader, S. M., and Sol, D. (2013). Innovating innovation rate and its relationship with brains, ecology and general intelligence. Brain Behav. Evol. 81, 143-145. doi: 10.1159/000348485

Manger, P. R. (2005). Establishing order at the systems level in mammalian brain evolution. Brain Res. Bull. 66, 282-289. doi: 10.1016/j.brainresbull.2005.05.002

Manger, P. R. (2006). An examination of cetacean brain structure with a novel hypothesis correlating thermogenesis to the evolution of a big brain. Biol. Rev. Camb. Philos. Soc. 81, 293-338. doi: 10.1017/S1464793106007019

Manger, P. R., Spocter, M. A., and Patzke, N. (2013). The evolutions of large brain size in mammals: the "over-700-gram club quartet." Brain Behav. Evol. 82, 68-78. doi: $10.1159 / 000352056$
Marino, L. (1998). A comparison of encephalization between odontocete cetaceans and anthropoid primates. Brain Behav. Evol. 51, 230-238.

Marino, L., Connor, R. C., Fordyce, R. E., Herman, L. M., Hof, P. R., Lefebvre, L., et al. (2007). Cetaceans have complex brains for complex cognition. PLoS Biol. 5:e139. doi: 10.1371/journal.pbio.0050139

Marino, L., Uhen, M. D., Frohlich, B., Aldag, J. M., Blane, C., Bohaska, D., et al. (2000). Endocranial volume of mid-late eocene archaeocetes (order: Cetacea) revealed by computed tomography: implications for cetacean brain evolution. J. Mamm. Evol. 7, 81-94. doi: 10.1023/A:1009417831601

Martin, R. D. (1981). Relative brain size and basal metabolic rate in terrestrial vertebrates. Nature 293, 57-60. doi: 10.1038/293057a0

McNally, L., Brown, S. P., and Jackson, A. L. (2012). Cooperation and the evolution of intelligence. Proc. R. Soc. B Biol. Sci. 279, 3027-3034. doi: 10.1098/rspb.2012.0206

Meester, J., and Setzer, H. W. (1977). The Mammals of Africa: An Identification Manual. Washington, DC: Smithsonian Institution Press.

Miller, A. K. H., and Corsellis, J. A. N. (1977). Evidence for a secular increase in human brain weight during the past century. Ann. Hum. Biol. 4, 253-257. doi: $10.1080 / 03014467700007142$

Montgomery, S. H., Geisler, J. H., McGowen, M. R., Fox, C., Marino, L., and Gatesy, J. (2013). The evolutionary history of cetacean brain and body size. Evolution 67, 3339-3353. doi: 10.1111/evo.12197

Navarrete, A., van Schaik, C. P., and Isler, K. (2011). Energetics and the evolution of human brain size. Nature 480, 91-93. doi: 10.1038/nature10629

Nedergaard, M., Ransom, B., and Goldman, S. A. (2003). New roles for astrocytes: redefining the functional architecture of the brain. Trends Neurosci. 26, 523-530. doi: 10.1016/j.tins.2003.08.008

Nowak, R. M., and Paradiso, J. L. (1983). Walker's Mammals of the World. Baltimore, MD: Johns Hopkins University Press.

Oboussier, H. (1972). Morphologische und quantitative neocortexuntersuchungen bei boviden, ein beitrag zur phylogenie dieser familie iii, formen über $75 \mathrm{~kg}$ körpergewicht. Mitt. Hambg. Zool. Mus. Inst. 68, 271-292.

Oboussier, H., and Möller, G. (1971). Zur kenntnis des gehirns der giraffidae (pecora, artiodactyla, mammalia)-ein vergleich der neocortex-oberflächengröße. Z. Säugetierkd. 36, 291-296.

Oboussier, H., and Schliemann, H. (1966). Hirn-körpergewichtsbeziehungen bei boviden. Z. Säugetierkd. 31, 464-471.

Oelschläger, H. H. A. (2008). The dolphin brain-a challenge for synthetic neurobiology. Brain Res. Bull. 75, 450-459. doi: 10.1016/j.brainresbull.2007.10.051

Oelschläger, H. H. A., Ridgway, S. H., and Knauth, M. (2010). Cetacean brain evolution: dwarf sperm whale (Kogia sima) and common dolphin (Delphinus delphis) - an investigation with high-resolution 3D MRI. Brain Behav. Evol. 75, 33-62. doi: 10.1159/000293601

Olff, H., Alonso, D., Berg, M. P., Eriksson, B. K., Loreau, M., Piersma, T., et al. (2009). Parallel ecological networks in ecosystems. Philos. Trans. R. Soc. Lond. B Biol. Sci. 364, 1755-1779. doi: 10.1098/rstb.2008.0222

Osborne, R. W., and Sundsten, J. W. (1981). Preliminary observations on 13 killer whale cranial volumes. Cetus 3, 12-13.

Perrin, W. F., Würsig, B. G., and Thewissen, J. G. M. (2002). Encyclopedia of Marine Mammals. San Diego, CA: Academic Press.

Pettit, A. (1905). Description des Encéphales de Grampus Griseus Cuv., de Steno Frontatus Cuv., et de Globicephalus Melas Traill, Provenant des Campagnes du Yacht Princesse-Alice. Résultats Camp. Sci. Accompl. Sur Son Yacht 31, 1-56.

Pianka, E. R. (1970). On r- and k-selection. Am. Nat. 104, 592-597.

Pilleri, G., and Busnel, R. G. (1969). Brain/body weight ratios in Delphinidae. Cells Tissues Organs 73, 92-97. doi: 10.1159/000143285

Pilleri, G., and Gihr, M. (1972). "Contribution to the knowledge of the cetaceans of Pakistan with particular reference to the genera (Neomeris), (Sousa), (Delphinus) and (Tursiops) and description of a new Chinese porpoise (Neomeris asiaeorientalis)," in Investigations on Cetacea, ed G. Pilleri (Bern: Institute of Brain Anatomy), 107-162.

Pirlot, P., and Stephan, H. (1970). Encephalization in chiroptera. Can. J. Zool. 48, 433-444. doi: 10.1139/z70-075

Povinelli, M., Panin, M., Mazzariol, S., Giurisato, M., Ballarin, C., Roncon, G., et al. (2014). Notes on the brain and encephalization quotient of two sperm whales with a synthesis of the literature and indications of a new method of extraction. Nat. Hist. Sci. 1, 131. doi: 10.4081/nhs.2014.202 
Puschmann, P. (1989). Zootierhaltung: Säugetiere. Frankfurt am Main: Deutsch Harri.

Radinsky, L. (1978). Evolution of brain size in carnivores and ungulates. Am. Nat. $112,815-831$.

Radinsky, L. (1981). Brain evolution in extinct South American ungulates. Brain Behav. Evol. 18, 169-187. doi: 10.1159/000121785

Raghanti, M. A., Spurlock, L. B., Robert Treichler, F., Weigel, S. E., Stimmelmayr, R., Butti, C., et al. (2015). An analysis of von Economo neurons in the cerebral cortex of cetaceans, artiodactyls, and perissodactyls. Brain Struct. Funct. 220, 2303-2314. doi: 10.1007/s00429-014-0792-y

Reader, S. M., and Laland, K. N. (2002). Social intelligence, innovation, and enhanced brain size in primates. Proc. Natl. Acad. Sci. U.S.A. 99, 4436-4441. doi: 10.1073/pnas.062041299

Reep, R. L., Finlay, B. L., and Darlington, R. B. (2007). The limbic system in mammalian brain evolution. Brain Behav. Evol. 70, 57-70. doi: $10.1159 / 000101491$

Ridgway, S. H. (1981). "Appendix IV: some brain morphometrics of the bowhead whale," in Tissues, Structural Studies, and other Investigations on the Biology of Endangered Whales in the Beaufort Sea (Final Report to the Bureau of Land Management, U.S. Department of Interior from the Department of Veterinary Science, University of Maryland, College Park, MD, 20742), ed T. F. Albert (Maryland: University Press), 837-844.

Ridgway, S. H., Flanigan, N. J., and McCormick, J. G. (1966). Brain-spinal cord ratios in porpoises: possible correlations with intelligence and ecology. Psychon. Sci. 6, 491-492. doi: 10.3758/BF03328106

Roth, G., and Dicke, U. (2005). Evolution of the brain and intelligence. Trends Cogn. Sci. 9, 250-257. doi: 10.1016/j.tics.2005.03.005

Sacher, G. A., and Staffeldt, E. F. (1974). Relation of gestation time to brain weight for placental mammals: implications for the theory of vertebrate growth. Am. Nat. 108, 593-615.

Sarko, D. K., Catania, K. C., Leitch, D. B., Kaas, J. H., and Herculano-Houzel, S. (2009). Cellular scaling rules of insectivore brains. Front. Neuroanat. 3:8. doi: 10.3389/neuro.05.008.2009

Schwerdtfeger, W. K., Oelschläger, H. H. A., and Stephan, H. (1984). Quantitative neuroanatomy of the brain of the La Plata dolphin, Pontoporia blainvillei. Anat. Embryol. (Berl.) 170, 11-19.

Shoshani, J., Kupsky, W. J., and Marchant, G. H. (2006). Elephant brain: part I: gross morphology, functions, comparative anatomy, and evolution. Brain Res. Bull. 70, 124-157. doi: 10.1016/j.brainresbull.2006.03.016

Shultz, S., and Dunbar, R. (2010). Encephalization is not a universal macroevolutionary phenomenon in mammals but is associated with sociality. Proc. Natl. Acad. Sci. U.S.A. 107, 21582-21586. doi: 10.1073/pnas.1005246107

Shultz, S., and Dunbar, R. I. M. (2006). Both social and ecological factors predict ungulate brain size. Proc. R. Soc. B Biol. Sci. 273, 207-215. doi: $10.1098 /$ rspb.2005.3283

Shultz, S., and Dunbar, R. I. M. (2010). Species differences in executive function correlate with hippocampus volume and neocortex ratio across nonhuman primates. J. Comp. Psychol. 124, 252-260. doi: 10.1037/a0018894
Sigmund, L. (1968). Das gehirn der schliefer als anatomische grundlage für den vergleich mit den ungulaten. Acta Soc. Zool. Bohemoslov. 32, $262-271$.

Starck, D. (1979). Vergleichende Anatomie der Wirbeltiere auf Evolutionsbiologischer Grundlage, 1st Edn. Berlin: Springer.

Stephan, H., Baron, G., and Frahm, H. D. (1988). Comparative size of brains and brain components. Comp. Primate Biol. 4, 1-38.

Stewart, C. (1902). Descriptive and Illustrated Catalogue of the Physiological Series of Comparative Anatomy Contained in the Museum of the Royal College of Surgeons of England. London: Taylor and Francis.

Storch, G., and Asher, R. J. (2015). "Placentalia, placentalier, placentatiere," in Spezielle Zoologie, eds W. Westheide and G. Rieger (Heidelberg: Spektrum Akademischer Verlag), 477-481.

Striedter, G. F. (2005). Principles of Brain Evolution. Sunderland, MA: Sinauer Associates.

Subcommittee on Laboratory Animal Nutrition Committee on Animal Nutrition and Board on Agriculture National Research Council (1995). Nutrient Requirements of Laboratory Animals. Washington, DC: Academic Press.

Tarpley, R. J., and Ridgway, S. H. (1994). Corpus callosum size in delphinid cetaceans. Brain Behav. Evol. 44, 156-165. doi: 10.1159/000 113587

van Dongen, P. A. M. (1998). "Brain size in vertebrates," in The Central Nervous System of Vertrebrates, eds R. Nieuwenhuyis, H. J. ten Donkelaar, and C. Nicholson (Berlin: Springer), 2099-2134.

Voogd, J., Nieuwenhuyis, R., Van Dongen, P. A. M., and ten Donkelaar, H. J. (1998). "Mammals," in The Central Nervous System of Vertrebrates, eds. R. Nieuwenhuyis, H. J. ten Donkelaar, and C. Nicholson (Berlin: Springer), 1637-2097.

Willemet, R. (2012). Understanding the evolution of mammalian brain structures; the need for a (new) cerebrotype approach. Brain Sci. 2, 203-224. doi: $10.3390 /$ brainsci2020203

Wilson, D. E., and Reeder, D. M. (2005). Mammal Species of the World: A Taxonomic and Geographic Reference. Baltimore, MD: JHU Press.

Wund, M., and Myers, P. (2011). Mammalia Animal Diversity Web. Available online at: http://animaldiversity.ummz.umich.edu/accounts/Mammalia/ (Accessed October 17, 2014).

Conflict of Interest Statement: The authors declare that the research was conducted in the absence of any commercial or financial relationships that could be construed as a potential conflict of interest.

Copyright (C) 2016 Steinhausen, Zehl, Haas-Rioth, Morcinek, Walkowiak and Huggenberger. This is an open-access article distributed under the terms of the Creative Commons Attribution License (CC BY). The use, distribution or reproduction in other forums is permitted, provided the original author (s) or licensor are credited and that the original publication in this journal is cited, in accordance with accepted academic practice. No use, distribution or reproduction is permitted which does not comply with these terms. 